\title{
Revisiting the Half Quanta and Defining Quantum Step Mechanics
}

\author{
Jean-Paul Auffray ${ }^{1}$, Mohamed S. El Naschie ${ }^{2 *}$ \\ ${ }^{1}$ Ex Courant Institute of Mathematical Sciences, New York University, New York, USA \\ ${ }^{2}$ Department of Physics, University of Alexandria, Alexandria, Egypt \\ Email: jpauffray@yahoo.fr, *Chaossf@aol.com
}

How to cite this paper: Auffray, J.-P. and El Naschie, M.S. (2016) Revisiting the Half Quanta Defining Quantum Step Mechanics. Journal of Modern Physics, 7, 1949-1952. http://dx.doi.org/10.4236/jmp.2016.714172

Received: September 5, 2016

Accepted: October 23, 2016

Published: October 27, 2016

Copyright $\odot 2016$ by authors and Scientific Research Publishing Inc. This work is licensed under the Creative Commons Attribution International License (CC BY 4.0).

http://creativecommons.org/licenses/by/4.0/ (c) (†) Open Access

\begin{abstract}
In a recent publication in this journal one of us introduced the concept of "half quanta" and used it to provide a new insight into the origin and nature of the presence of dark energy in the cosmos. We investigate in the present note the possibility that, in spite of this success, the concept of half quanta should be regarded to be an illegitimate intruder in the realm of modern Quantum Physics.
\end{abstract}

\section{Keywords}

Planck, Bohr, Dirac, Harmonic Oscillator, Quanta

\section{Introduction}

In 1900 or thereabouts, Berlin theoretician Max Planck accidentally uncovered the fact that motion in nature occurs in the form of elements each carrying the same amount, the same quantity-the same quantum-of dynamical action. He assigned to this element the symbol $b$ later changed to $h$.

While in England some thirteen years later (in 1913) Danish physicist Niels Bohr published his celebrated paper "On the Constitution of Atoms and Molecules" [1] in which he speculates that electrons in atoms circulate on circular "orbits" and therefore possess angular momentum. Setting aside (ignoring) the fact that angular momentum has the dimension of dynamical action-just as Planck's action element $h$ does-Bohr mimicked Planck and declared that angular momentum must also consist of "elements" for the designation of which he selected the (cumbersome) symbol $M_{0}$ thereby introducing - not necessarily on purpose but certainly in effect-a cacophony in the nascent theory of Quantum physics: physicists had suddenly not one but two competing elements of action to contend with, Pkanck's $h$ and Bohr's $M_{o}$ for rotational motion. 
A decade or so later, Cambridge physicist Paul Adrien Dirac aggravated the situation when he substituted his own symbol, the graphic (h-bar) $\hbar$. to designate the Bohr angular momentum "quantum element" $M_{0}$, whereby the symbol became known as the "Dirac constant".

Whatever Dirac's intimate motivation might have been when he took this initiative, it backfired on him: the "Dirac constant" soon became known and is commonly known nowadays as the Reduced Planckconstant.

In a recent publication [2], one of us considers the equation which yields the allowed "energy levels" and notably the ground state energy, for a 1-D quantum harmonic oscillator. This equation may be written in different ways. When the Dirac h-bar symbol $\hbar$ is used, a factor 0.5 occurs in the equation, leading to the consideration of "half quanta". The factor 0.5 disappears when the equation is written using Planck's $h$ instead of the Dirac h-bar symbol. The conclusions presented in [2] regarding the half quanta are presumably correct in their own rights. We present in this note another set of conclusions.

\section{The Devil Hides in Details}

The situation is quite simple. Consider a 1-D quantum harmonic oscillator oscillating with vibrational frequency $v$. Instead of $v$ one can just as well consider the angular frequency $w$ given by

$$
w=2 \pi v
$$

Keeping in mind that the reduced Planck constant is related to the "ordinary" Planck constant by the equation

$$
\hbar=h / 2 \pi
$$

one obtains readily for the 1-D quantum harmonic oscillator ground-state energy $(n=$ $0)$ :

$$
\begin{aligned}
& E_{0}=h v \\
& E_{0}=\frac{1}{2} \hbar w
\end{aligned}
$$

Thus Equation (3b) yields for the ground state $(n=0)$, the "half quanta" $E_{0}=1 / 2 \hbar w$. This does not happen with Equation (3a).

In [2], the following conclusion concerning the half quanta is proposed: "The innocent conclusion of the above half quanta is that our postulate gained mainly from experiments that quanta are indivisible cannot be as straight forward as one could naively have thought and who knows, it may open the door to unsuspected connections related to fractional-Hall effects and similar things".

In [3] we examined the possibility that equations such as Equations (3a) and (3b) above must properly be written so as to allow the elementary quantum $h$ to be considered to be an "active principle" apt to "express itself" or be expressed as the composition of two factors $a$ and $b$, here yielding for Equation (3a): 


$$
h=E_{0} \cdot d
$$

in which $d=1 / v$ measures a time duration.

A sharp difference thus opposes the two points of view we are briefly examining in this note. The difference is expressed forcefully in [2] in these terms: "A photon is an elementary particle, in fact the most elementary messenger particle of them all and $\mathrm{h} v$ has the same physical meaning as a photon".

Not so in [3], quite to the contrary.

\section{Inventing Quantum Step Mechanics}

The considerations presented in [2] constitute a coherent ensemble in the framework of the formalism called Quantum Mechanics by its co-inventor Werner Heisenberg, equally inventor of the Uncertainty Principle two years later (in 1927). By contrast, the scheme developed in [3] asserts that when the quantum generates an energy $E$ in the Void, it simultaneously generates a "time duration" $d$ such that $h=E d$ with Absolute Certainty. We propose to name the scheme thus conceived Quantum Step Mechanics (the quantum takes continuously but discontinuously steps to construct and deconstruct structures in the Void with Absolute Certainty \{3]).

\section{Conclusion}

Readers of this note are cordially invited to contribute their thoughts on how to reconcile the apparently irreconcilable results we have presented and to suggest how best to address this vexing question: is the Dirac h-bar symbol $\hbar$ a legitimate and useful innovation in Quantum Physics, or should it be mercilessly discarded henceforth as a meaninglessly disturbing intruder? (Figure 1).

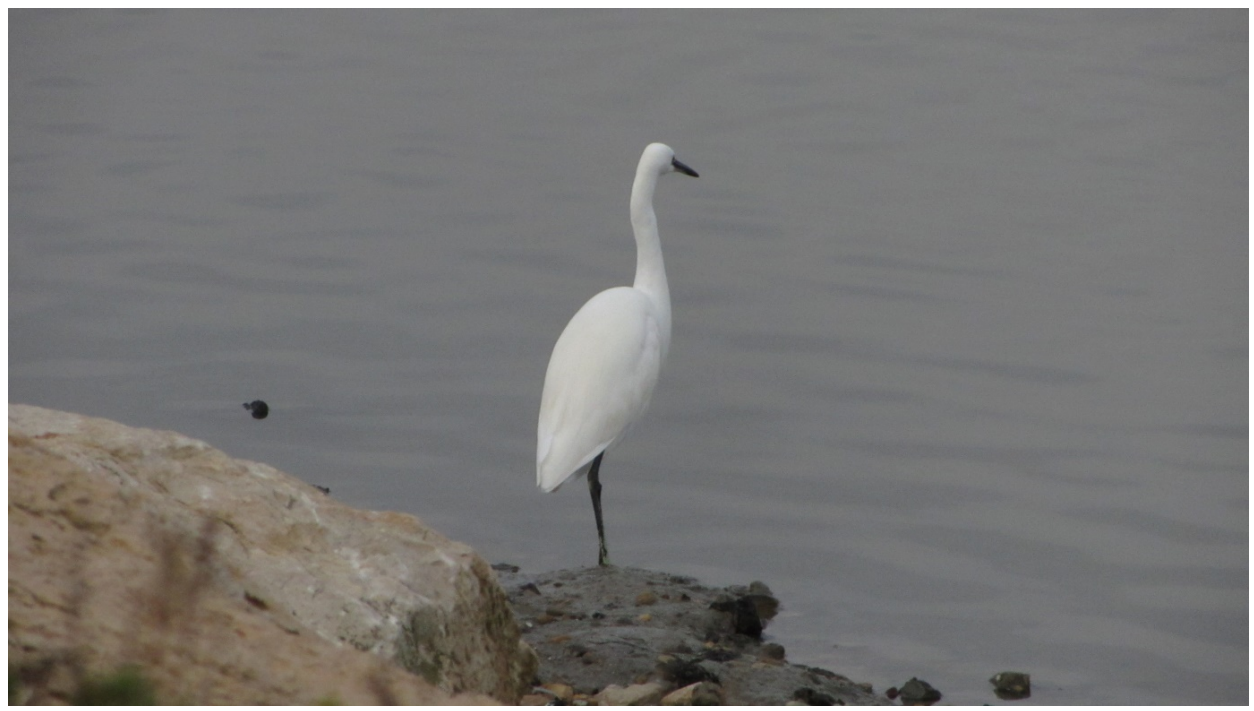

J. B. JPA private collection

Figure 1. On duty wondering: Will Dirac's h-bar symbol soon disappear from sight in the uncanny realm of Quantum Physics to yield the place to the delightful certainties of Quantum Step Mechanics? 


\section{Acknowledgements}

We wish to express our gratitude to Ms. Han Xu (Hellen), JMP Editorial Board Assistant, for her valuable help and kind advice in properly preparing this note for publication in this journal.

\section{References}

[1] Bohr, N.N. (1913) Philosophical Magazine, XXV, 24. http://dx.doi.org/10.1080/14786441308634955

[2] El Naschie, M.S. (2016) Journal of Modern Physics, 7, 1420-1428. http://dx.doi.org/10.4236/jmp.2016.712129

[3] Auffray, J.-P. and El Naschie, M.S. (2016) Journal of Modern Physics, 7, 156-161 http://dx.doi.org/10.4236/jmp.2016.71017

Submit or recommend next manuscript to SCIRP and we will provide best service for you:

Accepting pre-submission inquiries through Email, Facebook, LinkedIn, Twitter, etc. A wide selection of journals (inclusive of 9 subjects, more than 200 journals)

Providing 24-hour high-quality service

User-friendly online submission system

Fair and swift peer-review system

Efficient typesetting and proofreading procedure

Display of the result of downloads and visits, as well as the number of cited articles Maximum dissemination of your research work

Submit your manuscript at: http://papersubmission.scirp.org/

Or contact jmp@scirp.org 